\title{
Reconocimiento de nuestra acreditación internacional
}

\section{Recognition of our international accreditation}

\section{Milagros Carrasco Loyola ${ }^{1, a}$}

El Sistema Nacional de Evaluación, Acreditación y Certificación de la Calidad Educativa (SINEACE) mediante resolución $\mathrm{N}^{\circ}$ 000295-2020-SINEACE/CDAH-P del 23 de diciembre último, reconoce la acreditación internacional de nuestro Programa de Estomatología otorgada por el Instituto Internacional para el Aseguramiento de la Calidad del Centro Interuniversitario de Desarrollo Andino (IAC Cinda).

Si bien la acreditación es voluntaria, se ha establecido excepcionalmente que sea obligatorio para determinadas carreras como es el caso de Estomatología. El principal beneficio de la acreditación es la implementación de una cultura de evaluación y mejora continua que permite la toma de decisiones que conduzca al éxito de la institución.

El artículo 23 de la Ley $N^{\circ} 29837$ que crea el Pronabec, establece que entre las carreras profesionales de estudio a financiar se encontrarían aquellas acreditadas por el SINEACE. La acreditación nacional y la calidad de la institución son criterios para acceder a estos apoyos económicos.

Por otro lado, este reconocimiento, sumado a la acreditación institucional, nos permite establecer modalidades adicionales a la tesis y trabajo de suficiencia profesional para la obtención del título profesional, determinado por la Ley Universitaria. Nuestra facultad cuenta ahora con las normas y procedimientos para la obtención del título profesional de cirujano dentista actualizada que incluye dos modalidades más: el examen de suficiencia profesional y el taller de titulación. 